\title{
A Study on Correlation and Path Analysis for Yield and Yield Components in Rice (Oryza sativa L.) under Sodic Soil
}

\author{
Priyansh Singh, Pradeep Kumar Singh, Vinod Singh, \\ Om Prakash Verma and Ashim Debnath*
}

Department of Genetics \& Plant Breeding, Acharya Narendra Deva University of Agriculture \& Technology, Kumarganj, Ayodhya, (U.P.) India

*Corresponding author

Keywords

Sodic soil,

Correlation,

Path coefficient,

Grain yield, Rice

Article Info

Accepted:

04 October 2020

Available Online:

10 November 2020

\begin{abstract}
A B S T R A C T
Rice is known as major staple food crop in India by providing food to more than 70 per cent population. An experiment was carried out in Augmented Design for evaluation of eighty eight (88) diverse rice genotypes including three checks (NarendraUsarDhan 3, Jaya and CSR-36) under timely sown and irrigated conditions in sodic soil. The observation on eleven (11) characters was utilized for estimation of mean, range, least significant differences, correlations and path-coefficient. The genotype, NDRK 5018, followed by NDRK 50023, NDRK 5082, NDR 507, NDRK 5070, CSR 13 and NDRK 5029 produce highest grain yield per plant. High mean performance for several other characters was also found in the above mentioned genotypes and can be useful as parental materials in future breeding programme in sodic soil. Character association studies divulged that grain yield per plant (GYPP) showed high positive association with biological yield per plant (BYPP), spikelets per panicle (SPP), panicle bearing tillers per plant (TPP), flag leaf area (FLA) and harvest index (HI). Path analysis revealed that biological yield per plant (BYPP) and harvest index $(\mathrm{HI})$ are the major direct contributors towards expression of grain yield per plant (GYPP) whereas biological yield per plant (BYPP) came out as the most important indirect yield component. Hence, these characters need to emphasize as a selection criteria for rice improvement under sodic soil condition.
\end{abstract}

\section{Introduction}

Rice (Oryza sativa L.) is one of the important staple food crops with an annual production of 759.6 million tonnes (FAOSTAT, 2018). Rice feeds more than 70percent population in India and contributes especially towards the global food security. However, rapidly increasing population has forced us to look for another quantum jump in rice production.
Economics of Salt-Induced Land Degradation and Restoration Forum (2014) has found that about 6.73 million hectares of land is affected by salt. Out of which saline soil covers 2.96 million hectares and sodic soils cover 3.77 million hectares (Sharma and Chaudhari, 2012). Salt affected soil covered a total of 2.348 million hectares area in Indo-gangetic plains in India, out of which Uttar Pradesh has a share of 1.37 million hectares. To control 
the transport of salts it was reported initially through selective uptake by root cells and ions entering into the root along with water through symplastic and apoplastic pathways (Das et al., 2015). Based on the quantitative characters identification of genotypes is very important for rice improvement in sodic soil. Different statistical parameters like correlation and path analysis will be useful for the selection of appropriate genotypes for any environmental condition. Correlation studies helps in identifying the important traits that influence yield directly and indirectly. Selection for one component may simultaneously affect related traits in a favourable direction. Therefore, identifying the characters, which are closely related and have contributed to grain yield, becomes highly essential. The knowledge on association among different traits with yield and interrelationship is essential to improve the selection efficiency. Path coefficient analysis using correlations helps to increase in yield by identifying the most important characters for selection. Direct and indirect effect of different component traits on grain yield may differ from one environment to another. Therefore, it is essential to conduct path analysis under defined environmental conditions as the results may useful to that specific environment only (Rai et al., 2020). Keeping this information in mind a study was formulated to assess the character association in a set of rice genotypes for the traits contributing to yield under sodic soil condition.

\section{Materials and Methods}

The present investigation was conducted at the experimental farm of Acharya Narendra Deva University of Agriculture \& Technology, Ayodhya under the Department of Genetics and Plant Breeding with an aim to study the trait association among rice genotypes under sodic soil. The trial was laid out in natural sodic soil condition with a soil $\mathrm{pH}$ of 9.3 with $\mathrm{ECe}=2.24\left(\mathrm{dS}^{\mathrm{m}-1}\right)$. In augmented experimental design, a total of eighty eight (88) diverse germplasms were evaluated along with three checks (CSR 36, Jaya and Narendra Usar Dhan 3) in a fashion that field was sub-divided in to 8 blocks comprising of 14 plots each. Twenty eight (28) days old seedlings were transplanted in the experimental site under sodic soil by maintaining a spacing of $20 \mathrm{~cm} \times 15 \mathrm{~cm}$. For recording observation, randomly five (5) plants of each genotype were selected. Different yield related traits such as plant height in centimeter (PH), days to $50 \%$ flowering (DTF), flag leaf area in $\mathrm{cm}^{2}$ (FLA), panicle length in centimeter (PL), panicle bearing tillers per plant (TPP), spikelets per panicle (SPP), 1000-grain weight in gram (GW), spikelet fertility \% (SF\%), biological yield per plant in gram (BYPP), harvest-index $\%(\mathrm{HI})$ and grain yield per plant in gram (GYPP) were taken into consideration while taking observations. Analysis of variance was estimated with the recorded mean values of genotypes in each replication. Path coefficient analysis was conducted according to the methods of Dewey and Lu (1959). GYPP was considered to be dependent variable (effect) which was influenced by the other ten characters, the independent variables (causes). The variation in trait GYPP was unexplained by the ten causes which were presumed to be contributed by a residual factor (x).

\section{Results and Discussion}

The variation due to blocks was found significant or highly significant in analysis of variance for majority of the characters under study except for spikelet fertility where nonsignificant means squares were observed. The differences between the checks were also found to be highly significant except TPP, GW, BYPP, SF (\%) and HI where mean squares were non-significant. 


\section{Correlation coefficients}

It is desirable to understand the nature and magnitude of association between yield and its components for development of efficient breeding strategy and in this regard correlation coefficients play an important role. The estimates of correlation coefficients between different characters have been presented in Table 1. Highly significant and positive correlations was seen in grain yield per plant (GYPP)with majority of the characters under study such as plant height $(\mathrm{PH})$, panicle bearing tillers per plant (TPP), flag leaf area (FLA), harvest index (HI), biological yield per plant (BYPP) and spikelets per panicle (SPP) with an exception of days to 50\% flowering (DTF) and 1000grain weight $(\mathrm{GW})$ where non-significant association was observed. Harvest index (HI) showed highly significant and positive correlation value $(0.28)$ with panicle length (PL).In case of biological yield per plant (BYPP) the highest significant and positive correlation value $(0.62)$ was observed with panicle bearing tillers per plant (TPP) followed by spikelets per panicle (SPP) and plant height (PH).Significant positive correlation value was also observed in spikelets per panicle (SPP) with panicle length (PL), panicle bearing tillers per plant (TPP), plant height (PH) and flag leaf area (FLA) and there values are (0.44), (0.44), $(0.39)$ and (0.33) respectively. In case of panicle length (PL) the highest significant and positive correlation value (0.39) was observed with flag leaf area (FLA) followed by plant height $(\mathrm{PH})$ with value $(0.32)$. Panicle bearing tillers per plant (TPP) showed highly significant and positive correlation value with flag leaf area (FLA), days to $50 \%$ flowering (DTF) and plant height (PH) and their values are (0.19), (0.14) and (0.13) respectively. So genotypes performing well in sodic soil should have higher panicle bearing tillers per plant (TPP), flag leaf area (FLA), panicle length (PL), biological yield per plant (BYPP), spikelets per panicle (SPP) and harvest index (HI).Similar reports were found in rice where grain yield shows strong positive associations with other characters (Sarawgi et al., 2000; Shivani and Reddy, 2000; Sashidhar et al., 2005; Agahi et al., 2007; Bughio et al., 2009; Pandey et al., 2012; Lakshmi et al., 2014).In a recent study, grain yield per plant gives positive significant correlation in different crosses with majority of the important traits such as panicle per plant, spikelet fertility, biological yield and harvest index although traits like days to $50 \%$ flowering and spikelet fertility showed significant negative correlation (Dutt et al., 2020). A total fifty five (55) correlations were obtained between different character pairs. Out of thirty seven (37) significant correlation coefficients, only few estimates were negative in nature. The remaining 18 estimates of correlation coefficients were found to be nonsignificant in the present study. Due to correlated response, selection practiced for one character also brings improvement in other traits. Present study represents a number of traits which are correlated and take part in improving yield and its component in respect to sodic soil condition. A sensible compromise would be required for obtaining maximum combined contribution towards grain yield in order to take care of the traits days to $50 \%$ flowering (DTF) and spikelet fertility (SF\%) where negative correlations was observed. The estimates of correlation coefficient observed in present study are broadly in conformity with a previous report in rice (Janardanam et al., 2002). Although in the present study out of fifty five (55) character pairs only one character shows significant negative correlation which revealed far less complex situation in respect of character associations as compare with general trait association encountered in rice. This would help researcher to maintain proper balance with yield and its components in 
reference with rice germplasm used in the study.

\section{Path coefficient analysis}

Path coefficient analysis is a statistical measure which separates the correlation coefficients into direct and indirect effects.
Direct effect represents the immediate effect on a dependent character by an independent one whereas effect of an independent character on a dependent one with the help of other independent characters is called as indirect effect. Residual effects give an idea of the effects which were not covered in the study.

Table.1 Estimates of correlation coefficients between different characters under sodic soil

\begin{tabular}{|c|c|c|c|c|c|c|c|c|c|c|c|}
\hline Characters/Traits & FLA & PH & TPP & PL & SPP & SF (\%) & GW & BYPP & HI & GYPP \\
\hline DTF & 0.12 & $0.29^{* *}$ & $0.14^{*}$ & -0.02 & $0.22^{*}$ & $-0.25^{* *}$ & $-0.04^{*}$ & $0.30^{* *}$ & $-0.01^{*}$ & 0.12 \\
\hline FLA & & $0.28^{* *}$ & $0.19^{* *}$ & $0.39^{* *}$ & $0.33^{* *}$ & $0.19^{*}$ & 0.03 & $0.41^{* *}$ & $0.16^{*}$ & $0.37^{* *}$ \\
\hline PH & & & $0.13^{*}$ & $0.32^{* *}$ & $0.39^{* *}$ & -0.01 & 0.10 & $0.52^{* *}$ & -0.03 & $0.39^{* *}$ \\
\hline TPP & & & & 0.08 & $0.44^{* *}$ & 0.07 & 0.06 & $0.62^{* *}$ & $0.26^{*}$ & $0.54^{* *}$ \\
\hline PL & & & & & $0.44^{* *}$ & 0.05 & $0.20^{* *}$ & $0.29^{* *}$ & $0.28^{* *}$ & $0.26^{*}$ \\
\hline SPP & & & & & & 0.03 & -0.17 & $0.56^{* *}$ & $0.21^{*}$ & $0.51^{* *}$ \\
\hline SF (\%) & & & & & & & 0.04 & 0.06 & 0.03 & $0.08^{*}$ \\
\hline GW & & & & & & & & 0.03 & $0.13^{*}$ & 0.07 \\
\hline BYPP & & & & & & & & & $0.14^{*}$ & $0.83^{* *}$ \\
\hline HI & & & & & & & & & & $\mathbf{0 . 3 4} * *$ \\
\hline
\end{tabular}

* Significant at $5 \%$ level

** Significant at $1 \%$ level

Table.2 Estimates of direct and indirect effects between grain yield per plant (GYPP) and its component characters under sodic soil

\begin{tabular}{|c|c|c|c|c|c|c|c|c|c|c|}
\hline Characters/Traits & DTF & FLA & PH & TPP & PL & SPP & $\begin{array}{c}\text { SF } \\
(\mathbf{\%})\end{array}$ & GW & BYPP & HI \\
\hline DTF & $\mathbf{- 0 . 0 5}$ & -0.002 & -0.03 & -0.004 & 0.002 & -0.007 & 0.006 & 0.003 & -0.007 & 0.006 \\
\hline FLA & 0.004 & $\mathbf{0 . 0 3}$ & 0.009 & 0.008 & 0.014 & 0.01 & 0.005 & 0.002 & 0.013 & 0.005 \\
\hline PH & -0.011 & -0.009 & $\mathbf{- 0 . 0 3}$ & -0.005 & -0.010 & -0.012 & 0.000 & -0.002 & -0.017 & 0.002 \\
\hline TPP & -0.006 & -0.009 & -0.006 & $\mathbf{- 0 . 0 3}$ & -0.003 & -0.017 & -0.003 & -0.003 & -0.023 & -0.010 \\
\hline PL & 0.003 & -0.022 & -0.017 & -0.004 & $\mathbf{- 0 . 0 5}$ & -0.024 & -0.003 & -0.011 & -0.016 & -0.015 \\
\hline SPP & 0.013 & 0.018 & 0.019 & 0.023 & 0.023 & $\mathbf{0 . 0 5}$ & 0.002 & -0.009 & 0.029 & 0.011 \\
\hline SF (\%) & 0.000 & 0.000 & 0.000 & 0.000 & 0.000 & 0.000 & $\mathbf{0 . 0 0 2}$ & 0.001 & 0.000 & 0.000 \\
\hline GW & -0.002 & 0.001 & 0.002 & 0.002 & 0.002 & -0.001 & 0.002 & $\mathbf{0 . 0 2 0}$ & 0.031 & 0.011 \\
\hline BYPP & 0.22 & 0.322 & 0.437 & 0.508 & 0.236 & 0.457 & 0.071 & 0.043 & $\mathbf{0 . 8 1 4}$ & 0.133 \\
\hline HI & -0.036 & 0.031 & -0.013 & 0.052 & 0.057 & 0.043 & 0.009 & 0.029 & 0.033 & $\mathbf{0 . 2 0 0}$ \\
\hline
\end{tabular}

Residual effects: 0.099

Bold figures represent direct effects

In the present study, under sodic soil a total of ten (10) independent characters were covered on dependent character grain yield per plant. The estimates of direct and indirect effects for grain yield and its components are presented in table 2. In the present investigation most of the characters showed negligible direct effects on grain yield per plant (GYPP) but biological 
yield per plant (BYPP) and harvest index (HI) showed a very positive direct effects value (0.814 and 0.200 respectively) on grain yield per plant (GYPP). In some similar studies, traits like biological yield per plant and harvest index has a direct contribution to grain yield per plant (Sashidhar et al., 2005; Pandey et al., 2012; Venkanna et al., 2014). Regarding indirect effects, biological yield per plant (BYPP) exhibited high order value on grain yield per plant (GYPP) via different components such as panicle bearing tillers per plant (TPP), spikelets per panicle (SPP), plant height $(\mathrm{PH})$, flag leaf area (FLA), panicle length (PL), days to $50 \%$ flowering (DTF) and harvest index (HI).The estimate of residual factor (0.099) was found to be low. Similar reports showed that biological yield per plant was found as an important contributor to grain yield in rice crop (Madhavilatha et al., 2005; Yadav et al., 2008; Venkanna et al., 2014).

It can be concluded that a smaller proportion of direct and indirect effects get high order values in the present investigation; this may be due to presence of very high genetic variability in the germplasm lines which leads to different kinds of character association and ultimately cancellation of each other. However, biological yield per plant and harvest index act as a major direct contributors towards grain yield. Therefore these characters need to be further validated for future rice breeding program.

\section{References}

Agahi, K., Fotokian, M.H. and Farshadfar, E. 2007.Correlation and path coefficient analysis for some yield-related traits in rice genotypes (Oryza sativa L.).Asian J. Plant sciences.6(3): 513-517.

Bughio, H.R., Asad, M.A., Odhano, I.A., Arain, M.A. and Bughio, M.S. 2009. Heritability, genetic advance and correlation studies of some important traits in rice. International J. of Biology and Biotechnology. 6(1/2): 37-39.

Das, P., Nutan, K. K., Singla-Pareek, S. L. and Pareek, A. 2015.Oxidative environment and redoxhomeostasis in plants, dissecting out significant contribution of major cellular organelles. Front. environ. sci.2: 70.

Dewey, D.R. and Lu, K.H. 1959. A correlation and path analysis of components of creasted wheat grass seed production. Agron. J. 57: 515-518.

Dutt, A., Singh, N., Chaudhary, A. and Singh, P.K 2020.Inter-relationship analysis for improvement of yield components in rice (Oryza sativa L.) under sodic soil. Journal of Pharmacognosy and Phytochemistry. 9(1): 1656-1658.

FAOSTAT.2018.World's crop production. Food and agricultural organization.

Janardanam, V., Nadarajan, N. and Jebraj, S. 2002. Correlation and path analysis in rice (Oryza sativa L.). Madras Agril. J.88 (10/12): 719-720.

Lakshmi, V. M., Suneetha, Y., Yugandhar, G. and Lakshmi, V. N. 2014. Correlation studies in rice (Oryza sativa L.).International Journal of Genetic Engineering and Biotechnology.5 (2): 121-126.

Madhavilatha, L., Sekhar, M.R., Suneetha, Y. and Srinivas, T. 2005. Genetic variability, correlation and path analysis for yield and quality traits in rice (Oryza sativa L.). Research on crops .6(3): 527-534.

Pandey, V.R., Singh, P.K., Verma, O.P. and Pandey, P. 2012. Interrelationship and path coefficient estimation in rice under salt stress environment. International J. of Agril. Res. 7(4): 169-184.

Rai, A., Rai, M., Tyagi, W., Kumar, A. and Borpatragohain, B. 2020. Correlation and path analysis studies of yield and 
yield components in rice (Oryza sativa L.). Multilogic in science.vol. $\mathrm{X}$, issue xxxiv, July.

Sarawgi, A.K., Rastogi, N.K., Verma, R. and Wade, L.J. 2000.Character association in improved shallow rainfed lowland rice.Oryza.32 (4): 271-276.

Sashidhar, H. E., Pasha, F., Manjunath, J., Vinod, M.S. and Adnan, K. 2005. Correlation and path coefficient analysis in traditional cultivars and doubled haploids lines of rainfed low land rice. Oryza. 42(2): 156-159.

Sharma, D. K. and Chaudhari, S. K. 2012. Agronomic research in salt-affected soils of India: An Overview. Indian J.
Agron.5(7): 175-185.

Shivani, D. and Reddy, N.S.R. 2000. Correlation and path analysis in certain rice (Oryza sativa L.) hybrids. Oryza. 37(3): 183-186.

Venkanna, V., Lingaiah, N., Raju, C. S. and Rao, V. T. 2014.Genetic studies for quality traits of $\mathrm{F}_{2}$ population in rice (Oryza sativa L.).International Journal of Applied Biology and Pharmaceutical Technology.5 (2): 125-127.

Yadav, S.C.,Pandey, M.K. and Suresh, B.G. 2008.Association, direct and indirect effect of yield attributing trait on yield in rice (Oryza sativa L.). Annals of Biology. 24(1): 57-62.

\section{How to cite this article:}

Priyansh Singh, Pradeep Kumar Singh, Vinod Singh, Om Prakash Verma and Ashim Debnath. 2020. A Study on Correlation and Path Analysis for Yield and Yield Components in Rice (Oryza sativa L.) under Sodic Soil. Int.J.Curr.Microbiol.App.Sci. 9(11): 1121-1126.

doi: https://doi.org/10.20546/ijcmas.2020.911.130 